\title{
Forced mastication increases survival of adult neural stem cells in the hippocampal dentate gyrus
}

\author{
YUKI AKAZAWA $^{1}$, TAKAMASA KITAMURA ${ }^{2}$, YURI FUJIHARA ${ }^{1}$, YOSHITAKA YOSHIMURA ${ }^{3}$, \\ MASATO MITOME $^{1,2}$ and TOMOKAZU HASEGAWA ${ }^{1}$ \\ ${ }^{1}$ Department of Pediatric Dentistry, Tokushima University Hospital; ${ }^{2}$ Department of Pediatric Dentistry, \\ Institute of Health Biosciences, University of Tokushima Graduate School, Tokushima 770-8504; \\ ${ }^{3}$ Department of Molecular Cell Pharmacology, Division of Oral Pathological Science, \\ Hokkaido University Graduate School of Dental Medicine, Sapporo 060-8586, Japan
}

Received September 20, 2012; Accepted November 12, 2012

DOI: $10.3892 / \mathrm{ijmm} .2012 .1217$

\begin{abstract}
In this study, we examined the effect of forced mastication on neurogenesis in the hippocampal dentate gyrus (DG) of adult mice. Six-week-old mice were subjected to either a hard or normal diet for 13 weeks. They received a daily injection of bromodeoxyuridine (BrdU) for 12 consecutive days beginning at 14 weeks of age. The number of BrdU-positive cells in the DG was counted 1 day after and 5 weeks after the final BrdU injection. The number of BrdU-positive cells 1 day after injection did not differ between the 2 diet groups. However, the number of BrdU-positive cells in the group fed the hard diet was significantly increased 5 weeks after BrdU injection compared to the group fed the normal diet. The results of the Morris water maze test showed that mice fed a hard diet required significantly less time to reach the platform than the control mice when tested at 10 days. Moreover, mice in the group fed the hard diet spent significantly more time in the former platform area than the group fed the normal diet, indicating that hard diet feeding improved spatial memory compared to normal diet feeding. Real-time PCR analysis showed that the expression of glutamate receptor $1 \mathrm{mRNA}$ was significantly increased in the group fed the hard diet compared with the group fed the normal diet. These results suggest that mastication increases the survival of adult neural stem cells in the hippocampal DG.
\end{abstract}

\section{Introduction}

The generation of neurons in the mammalian central nervous system (CNS) was traditionally believed to end by early

Correspondence to: Dr Tomokazu Hasegawa, Department of Pediatric Dentistry, Tokushima University Hospital, 3-18-15 Kuramoto, Tokushima 770-8504, Japan

E-mail: hasegawa@dent.tokushima-u.ac.jp

Key words: induced mastication, neural stem cell, survival, proliferation postnatal life. However, it has been shown that the adult mammalian brain contains self-renewable, multipotent neural stem cells (NSCs) that are responsible for neurogenesis and plasticity in specific regions of the adult brain $(1,2)$. In the hippocampus, newly generated neurons originate from stem cells in the subgranular zone of the dentate gyrus (DG), and neurogenesis continues throughout adult life $(3,4)$. Although the mechanisms by which neurons are generated from stem cells are not yet well known, studies have indicated that the number of newly generated hippocampal neurons in adults is influenced specifically by enriched environments, learning, and voluntary exercise $(5,6)$.

Mastication is a behavior that is closely related with CNS activities. Chewing causes regional increases in cerebral blood flow and neuronal activity in the human brain $(7,8)$. By contrast, it has been shown that reduced mastication and occlusal disharmony impair spatial memory and promote the degeneration of hippocampal neurons $(9,10)$. We, as well as others, have also previously demonstrated that reducing mastication by feeding mice a soft diet inhibits the survival of newly generated neurons in the DG $(11,12)$. However, it remains unknown whether the induction of mastication affects the differentiation, proliferation, or survival of newly generated cells in the adult DG. In this study, we aimed to investigate the effects of forced mastication by hard diet feeding on the differentiation and survival of NSCs in the adult DG.

\section{Materials and methods}

Animals. Six-week-old C57BL/6 mice were housed in standard cages. Room conditions were kept at a 12:12-h light/dark cycle and an ambient temperature of $22 \pm 2^{\circ} \mathrm{C}$. Animals were allowed free access to food and water. All animal procedures were performed in accordance with the guidelines for the Care and Use of Laboratory Animals of Tokushima University Graduate School of Dentistry.

Diet. Mice were fed a standard laboratory diet, MF (Oriental Yeast, Tokyo, Japan). To create a hard diet, MF chow was autoclaved. The hardness of the MF chow was significantly increased by 1.5 -fold by autoclave treatment (Fig. 1). Therefore, 
autoclaved normal diet chow was used as the hard diet to enforce mastication in this study.

Experimental conditions. The time schedule of this experiment is shown in Fig. 2. At 6 post-natal weeks, the animals were placed in standard cages ( 4 or 5 animals/cage). Control mice were allowed free access to the standard pellet (Fig. 2A). Mice in the experimental group were given free access to a hard diet (autoclaved normal diet) (Fig. 2B). The animals were maintained in each experimental condition for 8 weeks and then received bromodeoxyuridine (BrdU; Sigma-Aldrich, St. Louis, MO, USA) injections (50 mg/g body weight) intraperitoneally once a day for 12 consecutive days. One day after the last BrdU injection, half the mice in each group were given an overdose of anesthetic and perfused transcardially with cold $4 \%$ paraformaldehyde in $0.1 \mathrm{M}$ phosphate-buffered saline (PBS) (11). The remaining animals in each group were kept in their respective experimental conditions for 5 additional weeks and were perfused in a similar manner.

Body weight measurement. Throughout the experiment, the nutritional status of the mice was monitored by weighing the mice regularly once a week until the day of sacrifice.

Immunohistochemistry. Mice were sacrificed and perfused transcardially with cold $4 \%$ paraformaldehyde in $0.1 \mathrm{M}$ PBS as previously described (11). The brains were removed from the skulls and immersed in the same fixative for $5 \mathrm{~h}$ at $4^{\circ} \mathrm{C}$ with constant rotation followed by washing with PBS overnight at $4^{\circ} \mathrm{C}$. Coronal $50-\mu \mathrm{m}$ hippocampal sections were made using a vibratome and stored at $-10^{\circ} \mathrm{C}$ in cryoprotectant reagent (30\% sucrose, $30 \%$ ethylene glycol and $0.25 \mathrm{mM}$ polyvinylpyrrolidone in PBS) (11). Vibratome sections were rinsed in $1 \mathrm{X}$ Tris-buffered saline (TBS), blocked with $10 \%$ normal goat serum (NGS), 1X Triton X-100 in TBS for $1 \mathrm{~h}$, followed by incubation with primary antibodies overnight. The following primary antibodies were used: mouse monoclonal antibodies against neuronal nuclei (NeuN; 1:1,000; Millipore) and neuronal nitric oxide synthase (nNOS; 1:1,000; Santa Cruz Biotechnology, Inc.), rat-monoclonal antibodies against BrdU (1:20; Funakoshi), rabbit-polyclonal antibodies for c-Fos (1:10,000; Santa Cruz Biotechnology, Inc.). For evaluation of the changes in neural proliferation and survival in the DG, the BrdU in vivo labeling protocol was used. BrdU is incorporated only in the cells that are dividing and is integrated in the synthesized DNA enabling them to be detected immunohistochemically. The free-floating brain slices were initially treated with denatured solution $(12 \mathrm{~N} \mathrm{HCl}+1 \mathrm{X}$ TBS $)$ and incubated for $30 \mathrm{~min}$ at $37^{\circ} \mathrm{C}$. After washing in TBS, the sections were incubated for $1 \mathrm{~h}$ at room temperature with the appropriate secondary antibodies: anti-mouse Alexa $594(1: 1,000)$ and antirabbit Alexa 488 (1:1,000). Finally, nuclei were stained with 4',6-diamidino-2-phenylindole (DAPI). Slices were mounted, coverslipped in ProLong ${ }^{\circledR}$ antifade reagent (Invitrogen Life Technologies, Carlsbad, CA, USA) and examined under an epifluorescence microscope.

Volume measurement of the granular cell layer of the DG. Brain slices stained with anti-NeuN antibody were examined and images of the 12 sections were acquired using an epifluo-

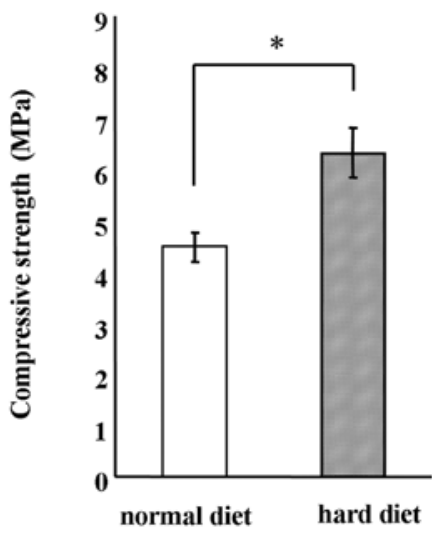

Figure 1. Hardness of normal diet (MF chow) and hard diet (autoclaved MF chow). The hardness of the diet used in this study is expressed as compressive strength (MPa). Autoclaved MF chow was significantly harder than untreated MF chow. Data represent the means $\pm \mathrm{SEM} ;{ }^{*} \mathrm{P}<0.01$ indicates a statistically significant difference.

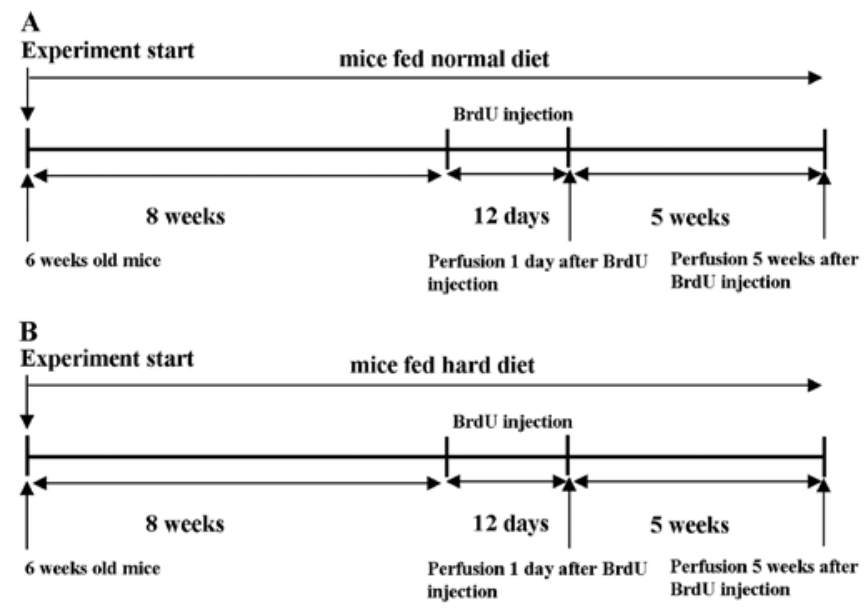

Figure 2. Time schedule of the experiment. Six-week-old mice were used in this study. Mice fed either (A) the normal diet or (B) the hard diet were maintained for 8 weeks and then injected with BrdU for 12 consecutive days. One day after the final BrdU injection, half the mice were perfused. The remaining animals in each group were maintained for 5 weeks and then perfused.

rescence microscope. To calculate the DG volume, the area of the granular cell layer was measured using ImageJ software and multiplied by the thickness of the sections $(50 \mu \mathrm{m})$ according to Cavalieri's principle (13).

Cell count. The DG was examined under a conventional epifluorescence microscope after the slices were immunohistochemically treated with specific antibodies. A total of 60 slices of $50-\mu \mathrm{m}$ coronal sections were originally stored in 5 separated tubes containing 12 slices in each tube. Sections from every $200 \mu \mathrm{m}$ across the whole hippocampus were selected (12 sections from anterior to posterior). BrdU, c-Fos and nNOS labeled cells were manually counted in each section by a blinded observer. A x20 objective lens was used for all counting (11). The labeled cells within the DG were examined for both the group fed the normal diet and the group fed the hard diet. 
Morris water maze. The Morris water maze task was preformed to test spatial learning. The task used a circular pool filled with water containing white ink. A platform was placed in the pool so that it was invisible at water level. The experiment was carried out after the 5 weeks following BrdU injection. Tasks were conducted between 09:00 and 15:00 during the light cycle. After training, mice underwent 3 trials/day for 10 consecutive days. During testing, mice were required to locate the platform, and escape latency time was recorded. Once mice located the platform, they were permitted to remain on it for $10 \mathrm{sec}$. If mice did not locate the platform within $90 \mathrm{sec}$, they were placed on the platform for $10 \mathrm{sec}$ and then removed from the pool, as previously described $(14,15)$.

Probe test. Mice were trained in the water maze as described above and then were subjected to a probe test. Each mouse was subjected to a probe test immediately after the final training trial on the 10th day. Before beginning the probe test, the platform was removed from the pool. Mice were released from the quadrant opposite to the previous platform quadrant, and the swimming was tracked for $90 \mathrm{sec}$, as previously described $(16,17)$.

Real-time PCR. Total RNA was isolated from 21-week-old mice. Mice were sacrificed by an overdose of anesthetic and the hippocampus was dissected in RNAlater (Sigma). Total RNA of hippocampal cells was isolated using the TRIzol reagent (Invitrogen Life Technologies) according to the manufacturer's instructions. RNA $(1 \mu \mathrm{g})$ was reversetranscribed to first-strand cDNA using a PrimeScript ${ }^{\mathrm{TM}}$ RT reagent kit (Takara Bio, Inc., Shiga, Japan) according to the manufacturer's instructions. A Thermal Cycler Dice real-time system (Takara Bio, Inc.) was used for real-time PCR (18-20). The cDNAs were amplified with SYBR ${ }^{\circledR}$ Premix Ex Taq and specific primer pairs for fibroblast growth factor (FGF)-1 (21), FGF-2 (22), epidermal growth factor (EGF) (23), vascular endothelial growth factor (VEGF) $(24,25)$, insulin-like growth factor-1 (IGF-1) (26), nerve growth factor (NGF), neurotrophin-3 (NT-3), brain-derived neurotrophic factor (BDNF), glial cell line-derived neurotrophic factor (GDNF), neuropeptide Y, $\beta$-tubulin III, 2',3'-cyclic-nucleotide phosphodiesterase (CNPase), microtubule-associated protein 2 (Map2), glial fibrillary acidic protein (GFAP), nestin, glutamate receptor 1 (GluR1) (27), glutamate receptor 2 (GluR2) (27), glutamate receptor 3 (GluR3) (27), glutamate receptor 4 (GluR4) (27), N-methyl D-aspartate receptor subtype 2B (NR2B) (28) and glyceraldehyde 3-phosphate dehydrogenase (GAPDH). Primers for NGF, NT-3, GDNF, $\beta$-tubulin III, CNPase, Map2, GFAP, nestin and GAPDH were designed with Perfect RealTime Primer Design software (Takara Bio, Inc.). The primers used in this study are listed in Table I. The PCR conditions were as follows: $10 \mathrm{sec}$ at $95^{\circ} \mathrm{C}$, followed by 40 cycles of $95^{\circ} \mathrm{C}$ for $5 \mathrm{sec}$ and $60^{\circ} \mathrm{C}$ for $30 \mathrm{sec}$, and finally, $15 \mathrm{sec}$ at $95^{\circ} \mathrm{C}$ and $30 \mathrm{sec}$ at $60^{\circ} \mathrm{C}$.

Statistical analysis. The results are presented as the means \pm SEM. For statistical analysis of the results, the Student's t-test and ANOVA (Scheffe's post hoc test) were used to compare the group fed the normal diet with the group fed the hard diet.
Table I. Primer list for real-time PCR $\left(5^{\prime} \rightarrow 3^{\prime}\right)$.

\begin{tabular}{|c|c|}
\hline Genes & Primer sequences \\
\hline GAPDH & $\begin{array}{l}\text { F: AACTTTGGCATTGTGGAAGG } \\
\text { R: ACACATTGGGGGTAGGAACA }\end{array}$ \\
\hline FGF-1 & $\begin{array}{l}\text { F: AGAGTACCGAGACTGGCCAGTAC } \\
\text { R: TCTGGCCATAGTGAGTCCGAG }\end{array}$ \\
\hline FGF-2 & $\begin{array}{l}\text { F: CCAACCGGTACCTTGCTATG } \\
\text { R: TATGGCCTTCTGTCCAGGTC }\end{array}$ \\
\hline EGF & $\begin{array}{l}\text { F: ACGGTTTGCCTCTTTTCCTT } \\
\text { R: GTTCCAAGCGTTCCTGAGAG }\end{array}$ \\
\hline VEGF & $\begin{array}{l}\text { F: GGAGATCCTTCGAGGAGCACTT } \\
\text { R: GGCGATTTAGCAGCAGATATAAGAA }\end{array}$ \\
\hline IGF-1 & $\begin{array}{l}\text { F: GTGTGGACCGAGGGGCTTTTACTTC } \\
\text { R: GCTTCAGTGGGGCACAGTACATCTC }\end{array}$ \\
\hline NGF & $\begin{array}{l}\text { F: CAGACCCGCAACATCACTGTA } \\
\text { R: CCATGGGCCTGGAAGTCTAG }\end{array}$ \\
\hline NT-3 & $\begin{array}{l}\text { F: CATTCGGGGACACCAGGTC } \\
\text { R: TTTGCACTGAGAGTTCCAGTGTTT }\end{array}$ \\
\hline BDNF & $\begin{array}{l}\text { F: GGTATCCAAAGGCCAACTGA } \\
\text { R: CTTATGAATCGCCAGCCAAT }\end{array}$ \\
\hline GDNF & $\begin{array}{l}\text { F: ACCCGCTTCCATAAGGCTTTA } \\
\text { R: CAGCCTTGTGCCGAAAGAC }\end{array}$ \\
\hline Neuropeptide Y & $\begin{array}{l}\text { F: GCAGAGGACATGGCCAGATAC } \\
\text { R: TGGATCTCTTGCCATATCTCTGTCT }\end{array}$ \\
\hline$\beta$-tubulin III & $\begin{array}{l}\text { F: GGGCATTCCAACCTT } \\
\text { R: AGCTCGGCGCCCTCTGTGTAGT }\end{array}$ \\
\hline CNPase & $\begin{array}{l}\text { F: CCTTAGCAACAGCCGAGTGGATA } \\
\text { R: GTTCCCAGATCACAAGCCAACA }\end{array}$ \\
\hline Map2 & $\begin{array}{l}\text { F: AATAGACCTAAGCCATGTGACATCC } \\
\text { R: AGAACCAACTTTAGCTTGGGCC }\end{array}$ \\
\hline GFAP & $\begin{array}{l}\text { F: GTACCAGGACCTGCTCAATG } \\
\text { R: TGTGCTCCTGCTTGGACTCCTT }\end{array}$ \\
\hline Nestin & $\begin{array}{l}\text { F: CTCCAAGAATGGAGGCTGTAGGAA } \\
\text { R: CCTATGAGATGGAGCAGGCAAGA }\end{array}$ \\
\hline GluR1 & $\begin{array}{l}\text { F: ATGCTGGTTGCCTTAATCGAG } \\
\text { R: ATTGATGGATTGCTGTGGGAT }\end{array}$ \\
\hline GluR2 & $\begin{array}{l}\text { F: TTGAGTTCTGTTACAAGTCAAGGGC } \\
\text { R: AGGAAGATGGGTTAATATTCTGTGGA }\end{array}$ \\
\hline GluR3 & $\begin{array}{l}\text { F: AACGCCTGTAAACCTTGCAGT } \\
\text { R: AGTCCTTGGCTCCACATTCC }\end{array}$ \\
\hline GluR4 & $\begin{array}{l}\text { F: CCAGGGCAGAGGCGAAG } \\
\text { R: CGTTTTCTCCCACACTCCCA }\end{array}$ \\
\hline NR2B & $\begin{array}{l}\text { F: TCCGCCGTGAGTCTTCTGTCTATG } \\
\text { R: CTGGGTGGTAAAGGGTGGGTTGTC }\end{array}$ \\
\hline
\end{tabular}

$\mathrm{F}$, forward; R, reverse.

\section{Results}

Effect of different food textures on mouse growth and dietary intake. Mice fed a normal diet between the ages of 6 and 20 weeks showed a significant difference in body weight 

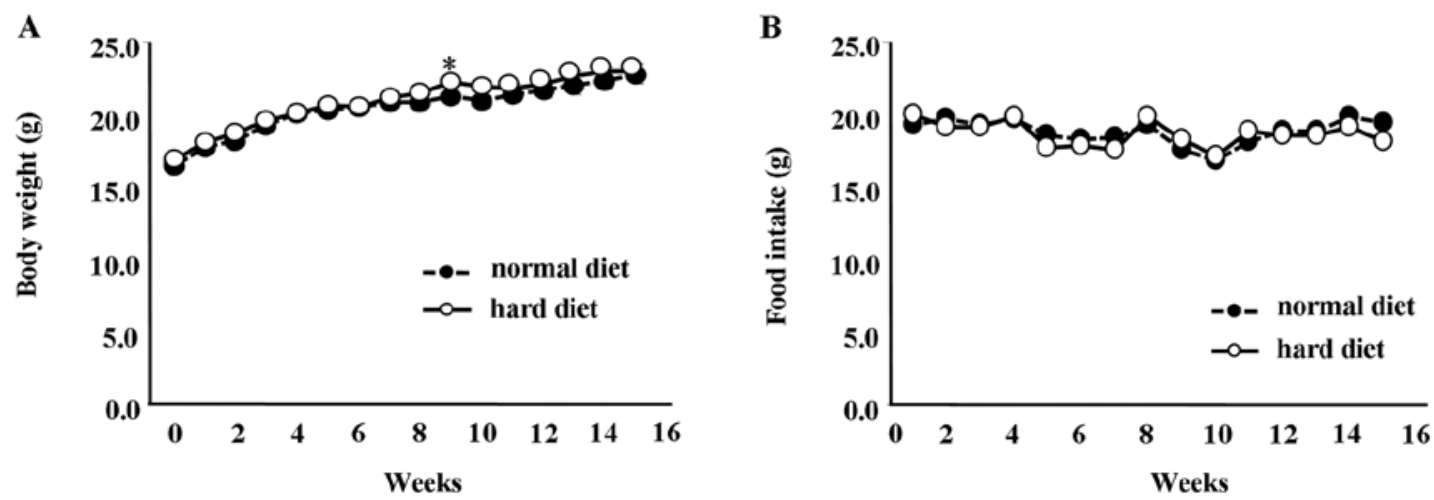

Figure 3. Weekly body weight and food intake of mice. (A) The change in body weight between the groups was not significantly different except when the mice reached 10 weeks of age. (A) However, body weight was only slightly different between the groups when the mice reached 10 weeks of age. (B) The amount of food intake between the groups was not significantly different. Data are presented as the means $\pm \mathrm{SEM} ;{ }^{*} \mathrm{P}<0.01$ indicates a statistically significant difference.

compared to the mice fed a hard diet at 11 weeks (Fig. 3A) $(\mathrm{P}<0.01)$. However, at all other time-points, the difference in body weight between the groups was not statistically significant. Similarly, the amount of food intake between the group fed the normal diet and the group fed the hard diet showed no significant differences (Fig. 3B).

Proliferation of newly generated cells in the DG. Representative images of BrdU-positive cells in the hippocampus 1 day after the BrdU injection are shown in Fig. 4 for the group fed the normal diet (Fig. 4A) and group fed the hard diet (Fig. 4B). The number of BrdU-positive cells in the DG 1 day after the BrdU injection was not significantly different between the groups (Fig. 4C).

Survival of newly generated cells in the DG. Representative images of BrdU-positive cells in the hippocampus 5 weeks after BrdU injections are shown for the group fed the normal diet (Fig. 5A) and the group fed the hard diet (Fig. 5B). There was a significantly larger number of BrdU-positive cells in the group fed the hard diet compared to the group fed the normal diet 5 weeks after BrdU injection $(\mathrm{P}<0.001)$ (Fig. 5C).

Hippocampal volume in mice fed the hard or normal diet. As shown in Fig. 6A, the hippocampal volume of the mice fed the hard diet was significantly larger than the hippocampal volume of the mice fed the normal diet when measured 5 weeks after $\mathrm{BrdU}$ injection $(\mathrm{P}<0.05)$.

Immunostaining of c-Fos and nNOS in the DG. The number of c-Fos-positive cells in the group fed the hard diet was greater than that in the group fed the normal diet 5 weeks after BrdU injection (Fig. 6B) $(\mathrm{P}<0.05)$. Similarly, the number of nNOSpositive cells in the DG was significantly increased in the group fed the hard diet compared to the group fed the normal diet 5 weeks after BrdU injection (Fig. 6C) $(\mathrm{P}<0.01)$.

Water maze experiment. The results of the Morris water maze experiment are shown in Fig. 7. The escape latency in each group decreased as the number of trials progressed. No significant difference in the escape latency was found between the group fed the hard diet and the group fed the normal diet from day 1 to 9 (Fig. 7A). Ten days after the beginning of the experiment, we observed a significant difference between the groups (Fig. 7A) $(\mathrm{P}<0.005)$. The results of the water maze probe test are shown in Fig. 7B. After 10 days of water maze experiments, the probe test was performed. When mice fed the hard diet were allowed to search for the platform, the period during which the mice focally searched around the former platform location was significantly longer than searches in other locations $(\mathrm{P}<0.01)$. By contrast, when mice fed the normal diet were subjected to the probe test, the only difference observed in their searches was between the time spent around the former platform location and the left side of the arena $(\mathrm{P}<0.05)$.

Effect of hard diet feeding on mRNA expression of growth factors, neurotrophic factors, NSC markers and receptors in the hippocampus. As is shown in Fig. 8, we analyzed the mRNA expression of growth factors, neurotrophic factors, NSC markers and receptors in the hippocampus between the group fed the hard diet and the group fed the normal diet at the end of the experiment. Real-time PCR analysis revealed that the mRNA expression of the growth factors, FGF-1, FGF-2, EGF, VEGF and IGF-1, was not affected by food texture (Fig. 8A). In addition, the expression of neurotrophic factors (NGF, NT-3, BDNF, GDNF and neuropeptide Y) (Fig. 8B) and NSC markers ( $\beta$-tubulin III, CNPase, Map2, GFAP and nestin) (Fig. 8C) did not differ between the group fed the hard diet and the group fed the normal diet. While the expression of the receptors, GluR2, GluR3, GluR4 and NR2B (Fig. 8D), was not affected by food texture, GluR1 mRNA expression was significantly increased in the group fed the hard $\operatorname{diet}(\mathrm{P}<0.01)$.

\section{Discussion}

To date, information as to how enforced mastication regulates NSC proliferation and survival in the hippocampus is lacking. To the best of our knowledge, this is the first report to demonstrate that the NSC survival in the hippocampus is increased and spatial memory is improved by forced mastication.

In this study, the normal diet was autoclaved to increase its hardness and thus force the mice to chew. With respect to body weight and food intake (Fig. 3), the growth of the mice was not affected by the autoclaved diet. Therefore, we inferred that 

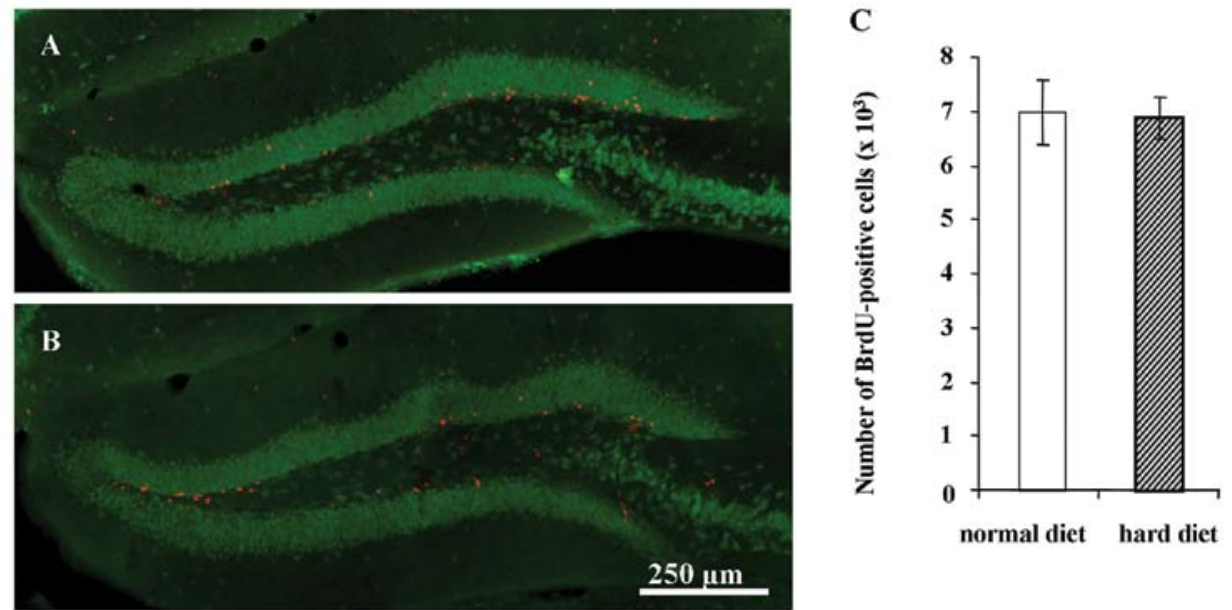

normal diet hard diet

Figure 4. Cell proliferation in the DG of mice 1 day after the final BrdU injection. Representative images of cells labeled with BrdU in the DG of mice fed (A) the normal diet and (B) the hard diet. (C) The number of BrdU-positive cells was not significantly different between the groups. Data are presented as the means \pm SEM. Red, BrdU; green, NeuN; bar, $250 \mu \mathrm{m}$.
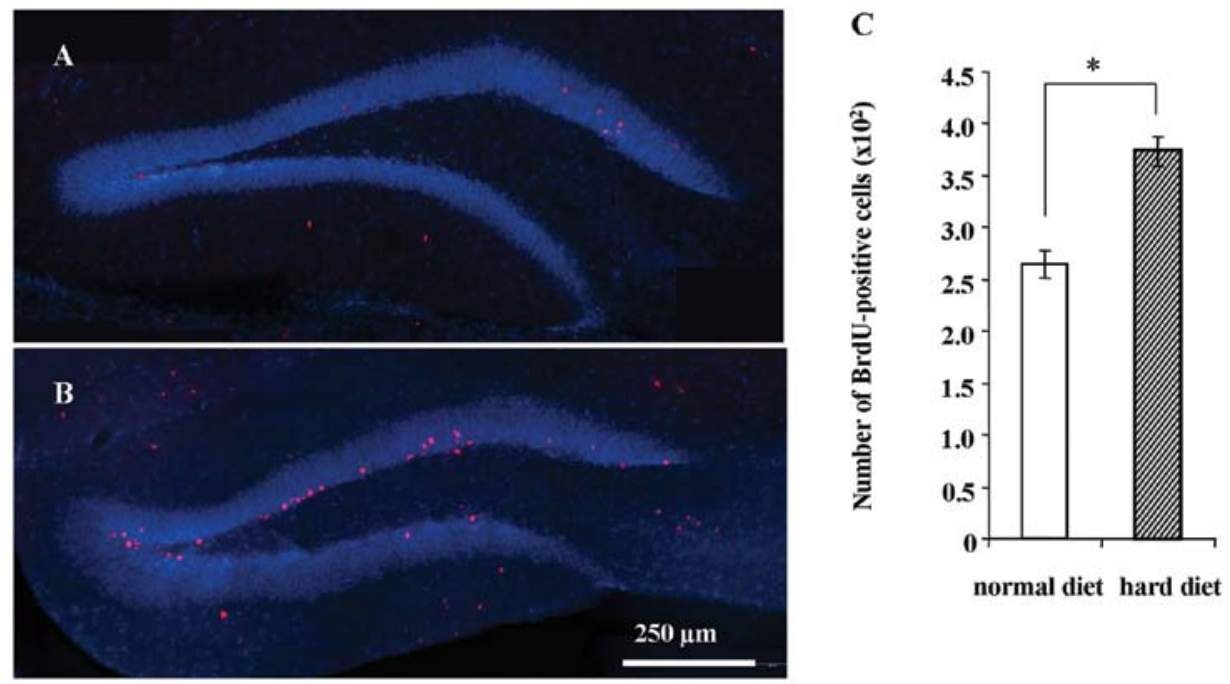

normal diet hard diet

Figure 5. Cell survival in the DG of mice 5 weeks after the final injection of BrdU. Representative images of cells labeled with BrdU in the DG of mice fed (A) the normal diet and (B) the hard diet. (C) The number of BrdU-positive cells in the group fed the hard diet was significantly larger than the group fed the normal diet. Data represent the means $\pm \mathrm{SEM} ;{ }^{*} \mathrm{P}<0.001$ indicates a statistically significant difference. Red, BrdU; blue, DAPI; bar, $250 \mu \mathrm{m}$.
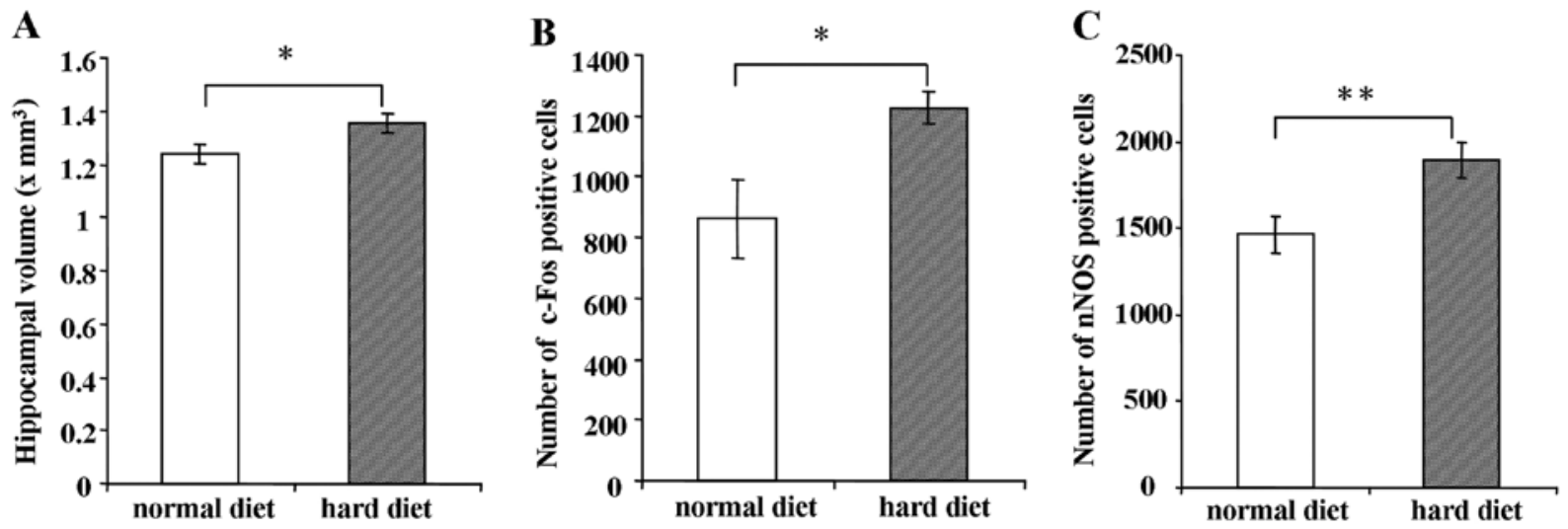

Figure 6. Hippocampal volume, c-Fos-positive cells, and nNOS-positive cells in the DG of mice 5 weeks after the final injection of BrdU. (A) Hippocampal volume in mice fed either the normal or the hard diet was evaluated. (B and C) The number of c-Fos-positive and nNOS-positive cells was determined via immunostaining. Data represent the means \pm SEM; (A and B) ${ }^{*} \mathrm{P}<0.05$ and ${ }^{* * *} \mathrm{P}<0.01$ indicates a statistically significant difference. 
A

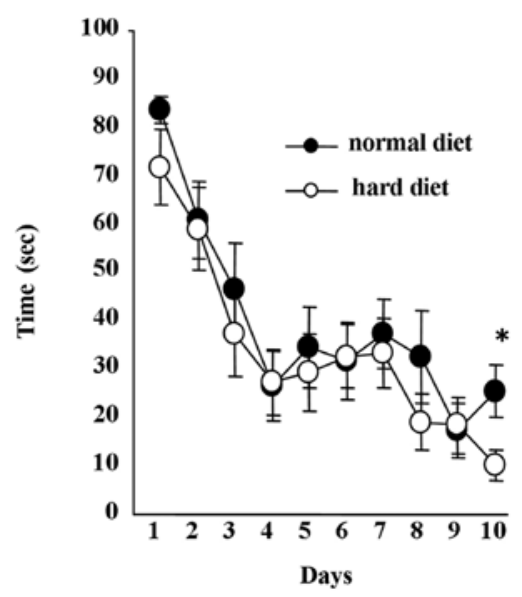

B

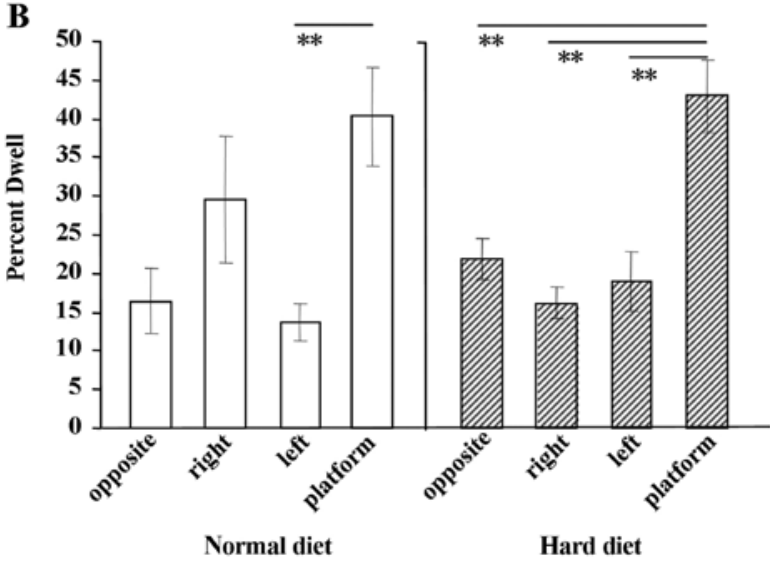

Figure 7. Spatial learning in the Morris water maze test. (A) Results are expressed as the means \pm SEM from 3 trials/day. (B) Results of the probe test. (A) ${ }^{*} \mathrm{P}<0.05$ and $(\mathrm{B}){ }^{* *} \mathrm{P}<0.01$ indicates a statistically significant difference.

the major nutritional components were not markedly different between the normal and the autoclaved normal diet.

We assessed the proliferation of subgranular progenitor cells in the DG of adult mice immediately after consecutive injections of BrdU. We observed that neither the hard diet nor the normal diet caused a change in the number of BrdUpositive cells (Fig. 4). These results indicated that the enforced mastication had no effect on the proliferation of progenitor cells as evaluated by BrdU labeling. Five weeks after the BrdU injections, a decrease in the number of BrdU-positive cells was observed not only in the group fed the normal diet but also in the group fed the hard diet (Fig. 5). However, we found that the number of surviving BrdU-positive cells was significantly increased in the group fed the hard diet compared to the group fed the normal diet (Fig. 5C). Therefore, these data suggest that forced mastication in the group fed the hard diet increased the survival rate of the newly generated cells in the DG.

Hippocampal volume in mice fed the hard diet was significantly increased compared to the mice fed the normal diet (Fig. 6A). Since a number of studies have shown that hippocampal volume affects memory functions (29), forced mastication due to a hard diet may be able to indirectly improve memory. For an assessment of neural activity after forced
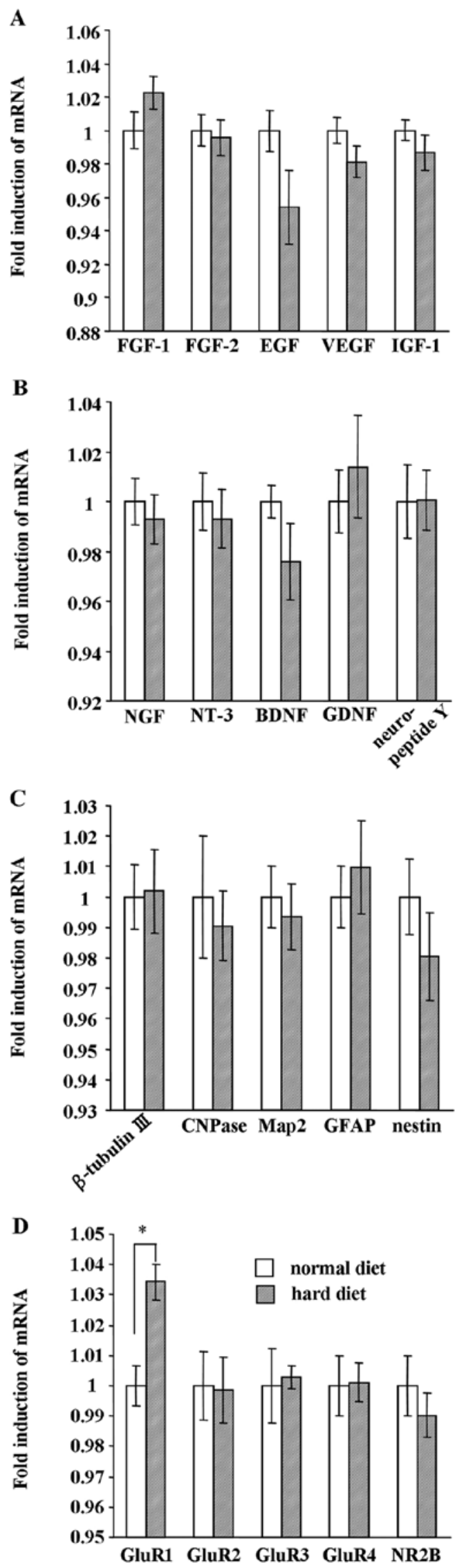

Figure 8 . Gene expression analysis in the hippocampus by real-time PCR. mRNA expression of (A) growth factors, (B) neurotrophic factors, (C) neural stem cell markers and (D) receptors were evaluated 5 weeks after the final BrdU injection. Control values from mice fed the normal diet were normalized to $100 \%$. Data represent the means \pm SEM; ${ }^{*} \mathrm{P}<0.01$ indicates a statistically significant difference. 
mastication, the expression of c-Fos in the DG of the group fed the hard diet and the group fed the normal diet was evaluated. It has been shown that the immunostaining of c-Fos is expressed in an activity-dependent manner and has been used as a marker for activated neurons in the DG $(30,31)$. In this study, since c-Fos levels in the DG of the mice fed the hard diet significantly increased compared with the mice fed the normal diet (Fig. 6B), mastication does indeed appear to influence neural activity in the DG.

Nitric oxide (NO) is an intercellular signaling molecule that is involved in several physiological processes $(32,33)$. At least 3 isoforms of NO synthase (NOS) have been identified in the CNS, including endothelial (eNOS), neuronal (nNOS) and inducible (iNOS) forms $(32,33)$. It has been reported that nNOS-knockout increases the survival rate of neuronal cells in the hippocampus (34). However, our results showed that the number of nNOS-positive cells in the mice fed the hard diet was significantly increased (Fig. 6C), and that the number of BrdU-positive cells in the DG of the group fed the hard diet was greater than that in the group fed the normal diet (Fig. 5C). Therefore, the survival of newborn cells during adult neurogenesis in the DG may depend upon other mechanisms in addition to nNOS signaling. For example, sensory-motor information taken from the oral cavity may reach the hippocampus, consequently affecting the neurogenesis rate. Another possibility is that the muscular contractions involved in mastication may increase cerebral blood flow, allowing an increase in the entry of growth factors into the DG that could affect the rate of neurogenesis.

The Morris water maze test was used to examine the effect of induced mastication on spatial learning ability, as previously described (35). Although the group fed the hard diet showed a significant decrease in escape latency only at 10 days compared with the group fed the normal diet (Fig. 7A) $(\mathrm{P}<0.005)$, the latency on the probe test after 10 days differed between the group fed the hard diet and the group fed the normal diet (Fig. 7B). This finding indicated that the group fed the hard diet spent significantly more time in the former location of the platform compared to all other locations. For this reason, we suggest that forced mastication can improve spatial learning ability.

We also assessed the effect of a hard diet on the mRNA expression of various growth factors, neurotrophic factors, neuronal stem cell markers, and receptors in the hippocampus by real-time PCR. Although several factors were examined, we observed a small but significant increase in the expression of GluR1 mRNA in the group fed the hard diet compared with the group fed the normal diet $(\mathrm{P}<0.01)$. GluRs are synaptic receptors located primarily on the membranes of neuronal cells (36). One of the major functions of GluRs appears to be the modulation of synaptic plasticity, memory and learning (36). Therefore, these changes in the group fed the hard diet may be attributed to the slight increase in GluR1 mRNA expression in the hippocampus (Fig. 8D), as well as in hippocampal volume (Fig. 6A) compared with the group fed the normal diet. However, since these results may be sensitive to the timing of experimentation, further experiments may be required to detect the critical periods of mRNA expression in the hippocampus.

In conclusion, forced mastication alters the survival rate and NSC activity in the DG. In addition, spatial memory was improved in the group fed the hard diet compared to the group fed the normal diet. These results suggest that mastication caused by daily food texture may improve or accelerate the recovery of spatial memory functions in the hippocampus, preventing senile dementia.

\section{Acknowledgements}

This study was supported in part by the Grants-in-Aid for Scientific Research (no. 21390548 to M.M. and no. 22592296 to T.H.) from the Ministry of Education, Culture, Sports, Science and Technology of Japan (2010-2014).

\section{References}

1. Gage FH: Mammalian neural stem cells. Science 287: 1433-1438, 2000.

2. Taupin P and Gage FH: Adult neurogenesis and neural stem cells of the central nervous system in mammals. J Neurosci Res 69: 745-749, 2002.

3. Altman J and Das GD: Autoradiographic and histological evidence of postnatal hippocampal neurogenesis in rats. J Comp Neurol 124: 319-335, 1965.

4. Kuhn HG, Dickinson-Anson H and Gage FH: Neurogenesis in the dentate gyrus of the adult rat: age-related decrease of neuronal progenitor proliferation. J Neurosci 16: 2027-2033, 1996.

5. van Praag H, Kempermann G and Gage FH: Running increases cell proliferation and neurogenesis in the adult mouse dentate gyrus. Nat Neurosci 2: 266-270, 1999.

6. Gould E, Beylin A, Tanapat P, Reeves A and Shors TJ: Learning enhances adult neurogenesis in the hippocampal formation. Nat Neurosci 2: 260-265, 1999.

7. Momose T, Nishikawa J, Watanabe T, Sasaki Y, Senda M, Kubota K, Sato Y, Funakoshi M and Minakuchi S: Effect of mastication on regional cerebral blood flow in humans examined by positron-emission tomography with ${ }^{15} \mathrm{O}$-labelled water and magnetic resonance imaging. Arch Oral Biol 42: 57-61, 1997.

8. Onozuka M, Fujita M, Watanabe K, Hirano Y, Niwa M, Nishiyama $\mathrm{K}$ and Saito S: Mapping brain region activity during chewing: a functional magnetic resonance imaging study. J Dent Res 81: 743-746, 2002.

9. Kato T, Usami T, Noda Y, Hasegawa M, Ueda M and Nabeshima T: The effect of the loss of molar teeth on spatial memory and acetylcholine release from the parietal cortex in aged rats. Behav Brain Res 83: 239-242, 1997.

10. Terasawa H, Hirai T, Ninomiya T, Ikeda Y, Ishijima T, Yajima T, Hamaue N, Nagase Y, Kang Y and Minami M: Influence of tooth-loss and concomitant masticatory alterations on cholinergic neurons in rats: immunohistochemical and biochemical studies. Neurosci Res 43: 373-379, 2002.

11. Mitome M, Hasegawa T and Shirakawa T: Mastication influences the survival of newly generated cells in mouse dentate gyrus. Neuroreport 16: 249-252, 2005.

12. Tsutsui K, Kaku M, Motokawa M, Tohma Y, Kawata T, Fujita T, Kohno S, Ohtani J, Tenjoh K, Nakano M, Kamada $\mathrm{H}$ and Tanne K: Influences of reduced masticatory sensory input from soft-diet feeding upon spatial memory/learning ability in mice. Biomed Res 28: 1-7, 2007.

13. Gundersen HJ, Bagger P, Bendtsen TF, et al: The new stereological tools: disector fractionator, nucleator and point sampled intercepts and their use in pathological research and diagnosis. APMIS 96: 857-881, 1988.

14. Fujioka A, Fujioka T, Tsuruta R, Izumi T, Kasaoka $S$ and Maekawa T: Effects of a constant light environment on hippocampal neurogenesis and memory in mice. Neurosci Lett 488: 41-44, 2011

15. Tauber SC, Bunkowski S, Ebert S, Schulz D, Kellert B, Nau R and Gerber J: Enriched environment fails to increase meningitis-induced neurogenesis and spatial memory in a mouse model of pneumococcal meningitis. J Neurosci Res 87: 1877-1883, 2009.

16. Moser E, Moser MB and Andersen P: Spatial learning impairment parallels the magnitude of dorsal hippocampal lesions, but is hardly present following ventral lesions. J Neurosci 13: 3916-3925, 1993. 
17. Stackman RW Jr, Lora JC and Williams SB: Directional responding of $\mathrm{C} 57 \mathrm{BL} / 6 \mathrm{~J}$ mice in the Morris water maze is influenced by visual and vestibular cues and is dependent on the anterior thalamic nuclei. J Neurosci 32: 10211-10225, 2012.

18. Hasegawa T, Chosa N, Asakawa T, Yoshimura Y, Ishisaki A and Tanaka M: Establishment of immortalized human periodontal ligament cells derived from deciduous teeth. Int J Mol Med 26: 701-705, 2010.

19. Asakawa T, Chosa N, Yoshimura Y, Asakawa A, Tanaka M, Ishisaki A, Mitome M and Hasegawa T: Fibroblast growth factor 2 inhibits the expression of stromal cell-derived factor $1 \alpha$ in periodontal ligament cells derived from human permanent teeth in vitro. Int J Mol Med 29: 569-573, 2012.

20. Hasegawa T, Chosa N, Asakawa T, Yoshimura Y, Fujihara Y, Kitamura T, Tanaka M, Ishisaki A and Mitome M: Differential effects of TGF- $\beta 1$ and FGF- 2 on SDF- $1 \alpha$ expression in human periodontal ligament cells derived from deciduous tooth in vitro. Int J Mol Med 30: 35-40, 2012

21. Arnold RS, Sun CQ, Richards JC, Grigoriev G, Coleman IM, Nelson PS, Hsieh CL, Lee JK, Xu Z, Rogatko A, Osunkoya AO, Zayzafoon M, Chung L and Petros JA: Mitochondrial DNA mutation stimulates prostate cancer growth in bone stromal environment. Prostate 69: 1-11, 2009.

22. Huang CC, Yeh CM, Wu MY, Chang AY, Chan JY, Chan SH and Hsu KS: Cocaine withdrawal impairs metabotropic glutamate receptor-dependent long-term depression in the nucleus accumbens. J Neurosci 31: 4194-4203, 2011.

23. Qu R, Li Y, Gao Q, Shen L, Zhang J, Liu Z, Chen X and Chopp M: Neurotrophic and growth factor gene expression profiling of mouse bone marrow stromal cells induced by ischemic brain extracts. Neuropathology 27: 355-363, 2007.

24. Fabel K, Fabel K, Tam B, Kaufer D, Baiker A, Simmons N, Kuo CJ and Palmer TD: VEGF is necessary for exercise-induced adult hippocampal neurogenesis. Eur J Neurosci 18: 2803-2812, 2003.

25. Cao L, Jiao X, Zuzga DS, Liu Y, Fong DM, Young D and During MJ: VEGF links hippocampal activity with neurogenesis, learning and memory. Nat Genet 36: 827-835, 2004.

26. Iida K, Del Rincon JP, Kim DS, Itoh E, Nass R, Coschigano KT, Kopchick JJ and Thorner MO: Tissue-specific regulation of growth hormone $(\mathrm{GH})$ receptor and insulin-like growth factor-I gene expression in the pituitary and liver of GH-deficient (lit/lit) mice and transgenic mice that overexpress bovine $\mathrm{GH}(\mathrm{bGH})$ or a bGH antagonist. Endocrinology 145: 1564-1570, 2004.
27. Destot-Wong KD, Liang K, Gupta SK, Favrais G, Schwendimann L, Pansiot J, Baud O, Spedding M, Lelièvre V, Mani S and Gressens P: The AMPA receptor positive allosteric modulator, S18986, is neuroprotective against neonatal excitotoxic and inflammatory brain damage through BDNF synthesis. Neuropharmacology 57: 277-286, 2009.

28. Boon WC, Diepstraten J, van der Burg J, Jones ME, Simpson ER and van den Buuse M: Hippocampal NMDA receptor subunit expression and water maze learning in estrogen deficient female mice. Brain Res Mol Brain Res 140: 127-132, 2005.

29. Ystad MA, Lundervold AJ, Wehling E, Espeseth T, Rootwelt H, Westlye LT, Andersson M, Adolfsdottir S, Geitung JT, Fjell AM, Reinvang I and Lundervold A: Hippocampal volumes are important predictors for memory function in elderly women. BMC Med Imaging 9: 17, 2009.

30. Kee N, Teixeira CM, Wang AH and Frankland PW: Preferential incorporation of adult-generated granule cells into spatial memory networks in the dentate gyrus. Nat Neurosci 10: 355-362, 2007.

31. Ahn SN, Guu JJ, Tobin AJ, Edgerton VR and Tillakaratne NJ: Use of c-fos to identify activity-dependent spinal neurons after stepping in intact adult rats. Spinal Cord 44: 547-559, 2006.

32. Bredt DS, Hwang PM and Snyder SH: Localization of nitric oxide synthase indicating a neural role for nitric oxide. Nature 347: 768-770, 1990.

33. Brenman JE and Bredt DS: Synaptic signaling by nitric oxide. Curr Opin Neurobiol 7: 374-378, 1997.

34. Fritzen S, Schmitt A, Köth K, Sommer C, Lesch KP and Reif A Neuronal nitric oxide synthase (NOS-I) knockout increases the survival rate of neural cells in the hippocampus independently of BDNF. Mol Cell Neurosci 35: 261-271, 2007.

35. Sharma S, Rakoczy S and Brown-Borg H: Assessment of spatial memory in mice. Life Sci 87: 521-536, 2010.

36. Peng S, Zhang Y, Zhang J, Wang $\mathrm{H}$ and Ren B: Glutamate receptors and signal transduction in learning and memory. Mol Biol Rep 38: 453-460, 2011. 